\title{
Bodegas, lagares y almazaras en el territorio de Kelin (siglos V-III a. C.): el caso de la Rambla de la Alcantarilla (Requena, Valencia)
}

\section{Cellars, stone wine and oil presses in the territory of Kelin $\left(5^{\text {th }}-3^{\text {rd }}\right.$ centuries BC $)$ : the case of la Alcantarilla ravine (Requena, Valencia)}

\author{
David Quixal Santos ${ }^{1}$ \\ Dpt. Prehistòria, Arqueologia i $\mathrm{H}^{\mathrm{a}}$ Antiga. Universitat de València \\ Guillem Pérez Jordà ${ }^{2}$ \\ G. I. Arqueobiología. Instituto de Historia. CSIC \\ Andrea Moreno Martín ${ }^{3}$ \\ Consuelo Mata Parreño \\ Yolanda Carrión Marco 5 \\ Dpt. Prehistòria, Arqueologia i $\mathrm{H}^{\mathrm{a}}$ Antiga. Universitat de València
}

\section{RESUMEN}

Las evidencias arqueológicas datan la expansión del cultivo de la vid en el territorio de Kelin durante los siglos V-III a. C., aunque los primeros indicios se fechan ya en el siglo VII a. C. Una de las singularidades de este territorio es la existencia de estructuras de piedra al aire libre para la producción de vino y aceite. Todas ellas se localizan en una zona concreta del territorio (Ramblas de la Alcantarilla y de los Morenos) (Requena, Valencia) y aparecen asociadas a materiales arqueológicos que permiten datarlas como ibéricas. En este artículo abordamos cómo se organiza el poblamiento en la rambla de la Alcantarilla y presentamos en detalle los yacimientos de la Rambla de la Alcantarilla y Solana de Cantos 2.

\section{SUMMARY}

Archaeological evidences date the expansion of grape vineyards in the territory of the Iberian Iron Age city of Kelin from the 5th to 3rd centuries BC; although the origins are documented in the 7th $\mathrm{BC}$. One of the singularities of this territory is the existence of outdoors stone structures for the production of wine and oil. All are located in a specific area of the territory (la Alcantarilla and Los Morenos ravines) (Requena, Valencia), and are associated with archaeological materials that allow date them as Iberian. In this paper we approach the rural settlement pattern in la Alcantarilla ravine and we present in detail the

\footnotetext{
${ }^{1}$ david.quixal@uv.es

${ }^{2}$ guillem.perez@csic.es

3 andrea.moreno@uv.es

4 consuelo.mata@uv.es

${ }^{5}$ yolanda.carrion@uv.es
}

archaeological sites of Rambla de la Alcantarilla and Solana de Cantos 2.

PALABRAS CLAVE: Lagar; Bodega; Almazara; Hábitat rural; Edad del Hierro.

KEY WORDS: Wine press; Cellar; Oil Press; Rural habitat; Iberian Iron Age.

Dentro del proyecto de investigación del territorio ibérico de Kelin (Caudete de las Fuentes, Valencia), en 2005 se iniciaron una serie de excavaciones en yacimientos ya catalogados, con el fin de conocer el funcionamiento de los enclaves de pequeño tamaño y ubicados en zonas llanas. En ese mismo año, se excavó Rambla de la Alcantarilla; en 2006, Solana de Cantos 2; en 2007 y 2008, El Zoquete (Pérez Jordà et alii 2007; Quixal et alii 2008); y entre 2010 y 2012, la Casa de la Cabeza (Quixal et alii 2010; 2011 y 2012a). Yacimientos todos ellos en el término municipal de Requena y cuyas intervenciones fueron sufragadas en todos los casos por el Servei d'Investigació Prehistòrica de la Diputació de València. Estas actuaciones se completaron además con prospecciones sistemáticas en las zonas aledañas.

En este trabajo vamos a tratar los dos primeros yacimientos citados: Rambla de la Alcantarilla y Solana

Copyright: (C) 2016 CSIC. Este es un artículo de acceso abierto distribuido bajo los términos de una licencia de uso y distribución Creative Commons Attribution (CC-by) España 3.0. 
de Cantos 2, muy próximos entre sí, a ambos lados de la rambla de la Alcantarilla, con el fin de completar las noticias parciales publicadas con anterioridad (Mata et alii 1997: 47; Pérez Jordà 2000; Pérez Jordà et alii 2000: 161; Grau Almero et alii 2001: 97-98; Mata et alii 2005: 739-740; Mata et alii 2009; Mata et alii 2010: 40-41; Quixal et alii 2011; Pérez Jordà et alii 2013; Pérez Jordà et alii 2015). Para un mejor conocimiento del poblamiento en la rambla de Los Morenos remitimos a los trabajos ya publicados (Mata et alii 1997; Pérez Jordà 2000; Martínez Valle et alii 2011; Martínez Valle y Hortelano 2011; Martínez Valle y Maronda 2013; Martínez Valle 2014).

La rambla de la Alcantarilla pese a tener un caudal muy irregular, tiene un largo recorrido N-S desde las inmediaciones del río Madre, en plena meseta de Requena-Utiel, hasta desembocar en la rambla de La Albosa, ya en el inicio de la depresión del río Cabriel. Esta rambla tiene otra de trazado paralelo y fisonomía muy similar en su lado oriental, la rambla de Los Morenos, con escasos 1,5-2 km de distancia en el tramo final de ambos cursos. Dicha similitud alcanza incluso al ámbito de la Arqueología, pues ambas presentan indicios de una semejante organización del poblamiento en época ibérica. Esto se tradujo en una sistemática explotación del medio y los recursos disponibles en pro de la vitivinicultura y, en menor medida, la oleicultura, tal y como atestigua la presencia al aire libre de lagares y almazaras rupestres, conocidos en la comarca como "pilillas".

Hoy en día ambas ramblas están catalogadas como zona de erosión potencial muy elevada ${ }^{6}$. Es, por tanto, un área cuyo paisaje actual está desvirtuado respecto al que debió existir en la antigüedad, ya que las pendientes y barrancadas que las forman no serían tan marcadas, permitiendo cultivar las zonas de ribera e incluso las laderas y piedemontes (Ruiz Pérez 2011; Pérez Jordà et alii 2013: 156, figs. 2 y 5). La comparación de las fotografías aéreas de 1956 con las ortofotos actuales muestra cómo esta zona apenas ha sido modificada antrópicamente. Más bien al contrario, se han abandonado los campos de cultivo y las pequeñas zonas residenciales, produciéndose paralelamente un aumento de la masa forestal.

Esta zona geográfica y sus yacimientos formaron parte, en la época que nos ocupa, del territorio dependiente de la ciudad de Kelin (Caudete de las Fuentes, Valencia) (unos $2000 \mathrm{~km}^{2}$ ). Los trabajos arqueológicos llevados a cabo han mostrado una ocu-

\footnotetext{
${ }^{6}$ Erosión actual entre las 40-100 Tm/ha. al año, según la cartografía temática de la Generalitat Valenciana (http://cartoweb.cma.gva.es/visor/index.html?modo=web\&temas=Web_ Serie_Tematica).
}

pación ininterrumpida desde el siglo viI al primer cuarto del I a. C., permitiendo estudiar su evolución tanto a nivel urbanístico como de cultura material y recursos económicos. Desde este lugar central se organizaba y administraba el territorio a partir de un patrón de asentamiento jerarquizado, con núcleos de diferente rango y funcionalidad como fortificaciones, pueblos, granjas y diversos establecimientos rurales (Mata 1991; Mata et alii 1997; Mata et alii 2001; Mata 2006; Pérez Jordà et alii 2007b; Quixal et alii 2008; Mata et alii 2009; Moreno 2011).

\section{LOS YACIMIENTOS: ESTRUCTURAS Y MATE- RIALES}

De $\mathrm{N}$ a $\mathrm{S}$, siguiendo la rambla, tenemos identificados un total de seis yacimientos, que presentan una gran diversidad en cuanto a entidad, estructuras, funcionalidad y materiales (Fig. 1).

\section{Casa de la Alcantarilla}

Este yacimiento está situado en la ladera occidental de la rambla de la Alcantarilla ${ }^{7}$, alrededor del caserío que le da nombre y junto a un manantial aprovechado por el mismo. Buena parte de su superficie está aterrazada para cultivo de la viña, aunque también hay áreas yermas y otras abandonadas en épocas recientes.

Su prospección sistemática (2006) aportó una dispersión de materiales de unas 12 ha y una concentración de 1,5 ha al SO de la casa. En el corte del camino, que conduce al caserío, se vieron restos de $\operatorname{muros}^{8}$. La superficie a prospectar se dividió en seis sectores (AF) correspondientes a los campos de cultivo en los que se encontraron materiales con diferentes densidades y horquillas cronológicas (Fig. 2). Material ibérico se encontró en todos ellos, exceptuando el E, donde tan sólo hay escasas cerámicas romanas. El grueso de materiales imperiales se concentra en los sectores E-F, mientras que los A-D albergan la mayoría de los ibéricos. Dentro de estos últimos podemos destacar que las cerámicas más antiguas se encontraron en los sectores D y, sobre todo, el B; mientras que los sectores $\mathrm{C}$ y, de nuevo, el D presentaron cerámicas ibéricas del siglo II a. C. y romano-republicanas.

\footnotetext{
${ }^{7}$ Fue localizado en 2005 gracias a la información de D. Antonio Piqueras, vecino de la aldea de Campo Arcís.

${ }^{8}$ En las prospecciones realizadas en 2010 por otro equipo de investigación, tal y como consta en el Inventario de Yacimientos Arqueológicos de la Generalitat Valenciana (IYAGV), el mismo lugar fue fichado como "Fuente Alcantarilla".
} 


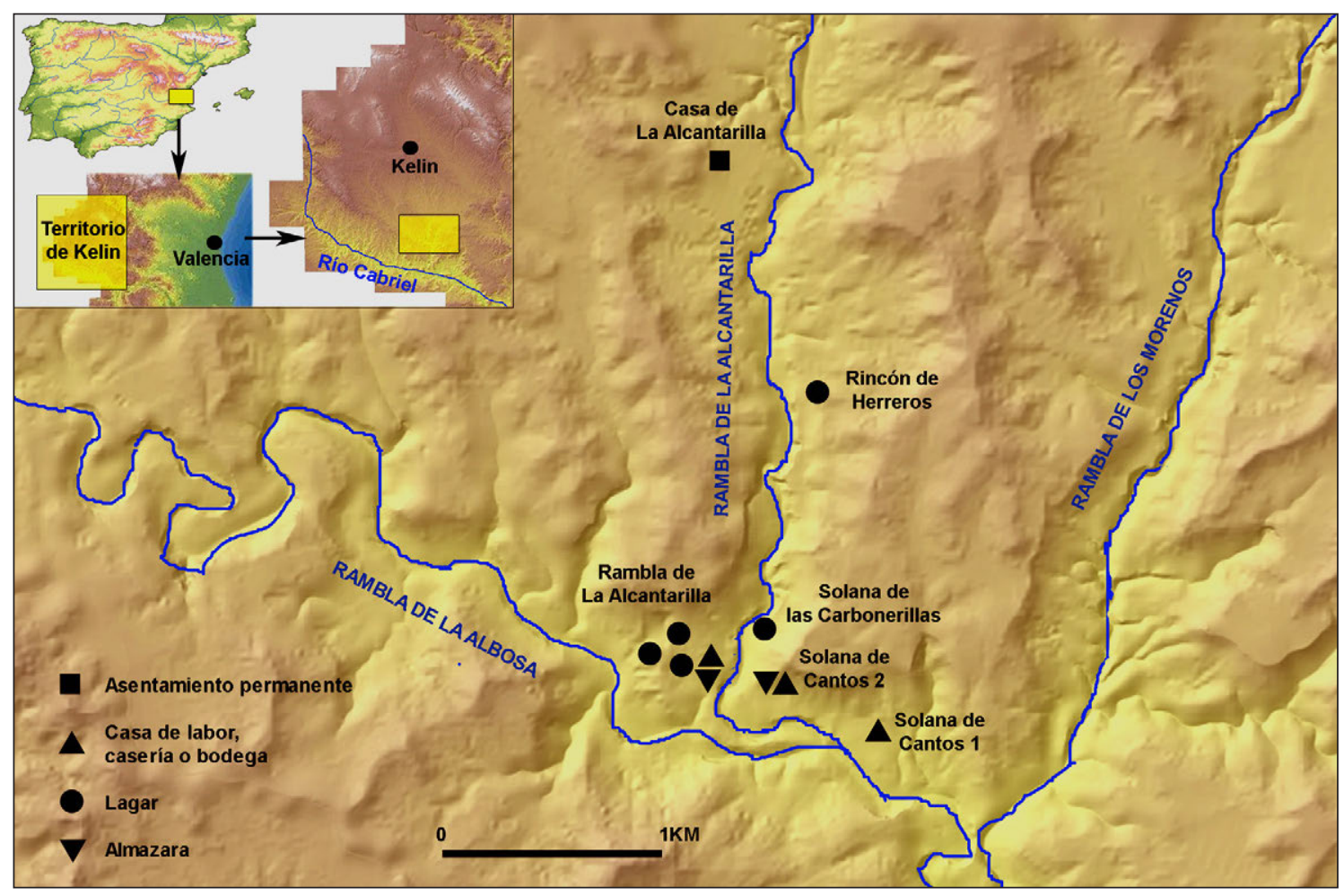

Figura 1. Mapa de la rambla de la Alcantarilla y sus yacimientos.

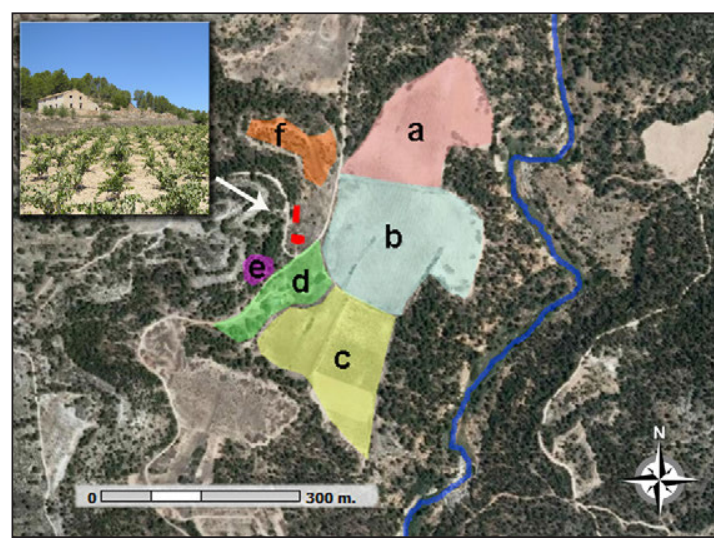

Figura 2. Mapa de los diferentes sectores de la Casa de la Alcantarilla.

Por lo tanto, el yacimiento presenta una larga diacronía, con una aparente estratigrafía horizontal, desde los siglos VI-V a. C. por la presencia de un ánfora fenicia occidental (Fig. 3.1), bordes subtriangulares (Fig. 3.5), producciones ibéricas grises, imitaciones de formas clásicas y decoraciones bícromas (Fig. 3.6); del siglo II a. C. hay barniz negro campaniense, ánforas Dressel 1 y cerámica ibérica con decoración figurada; y de época altoimperial, ánfora africana, cerámica común, TSG y TSH. Entre las cerámicas ibéricas se han documentado la mayoría de los grupos funcionales de la tipología de Mata y Bonet (1992), con predominio de los recipientes de despensa (lebetes y tinajillas) (Fig. 3.3 a 3.6), seguidos de ánforas y tinajas (Fig. 3.1 y 2) y vajilla de mesa (jarros, platos o páteras) (figs. 3.7 a 3.9), así como cerámica de cocina (Fig. 3.12) y piezas menos frecuentes como tejuelos, imitaciones de formas clásicas (Mata y Quixal 2014, figs. 1 y 2) (Fig. 3.10) y una forma indeterminada con engobe marrón tanto por el interior como por el exterior (Fig. 3.11).

Además de las importaciones fenicias y romanas, las cerámicas más interesantes son dos fragmentos con decoración figurada compleja y un asa de ánfora ibérica con marca impresa. En los primeros se aprecia la parte delantera de una posible ave con fuertes garras (Fig. 4.1) y el tronco de un ser indeterminado junto a otros elementos vegetales (Fig. 4.2), pero su estado fragmentario no permite mayores precisiones (Quixal 2015: 148 y Fig. 192). El cuño sobre el ánfora tiene forma cuadrada, compuesta por dos triángulos, uno de ellos dividido a su vez en dos triángulos menores (Fig. 4.3).

En conclusión, la Casa de la Alcantarilla sería un asentamiento ubicado en cotas bajas, cerca de sus 


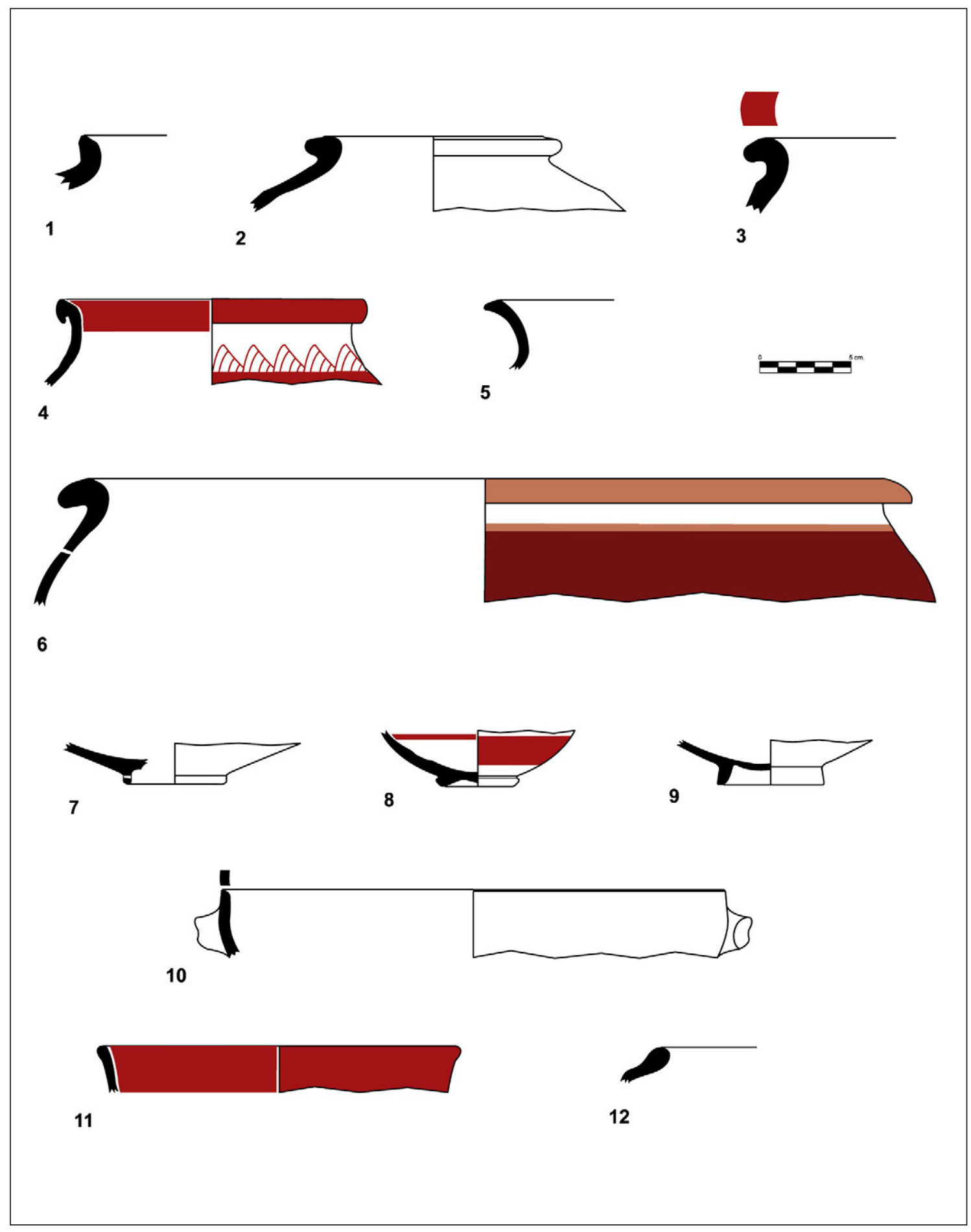

Figura 3. Cerámicas de Casa de la Alcantarilla: 1, Ánfora fenicia occidental (zona B); 2, Ánfora ibérica (zona D); 3, Tinaja (zona C); 4, Tinajilla con cuello (zona D); 5, Tinajilla con cuello (zona B); 6, Lebes con orificio de lañado (zona D); 7, Base anillada de plato con orificio de suspensión (zona B); 8, Base anillada de plato (zona C); 9, Base alta de plato, cerámica gris (zona D);10, Imitación de copa; 11, Posible imitación con engobe marrón (zona B); 12, Olla de cocina (zona B). 


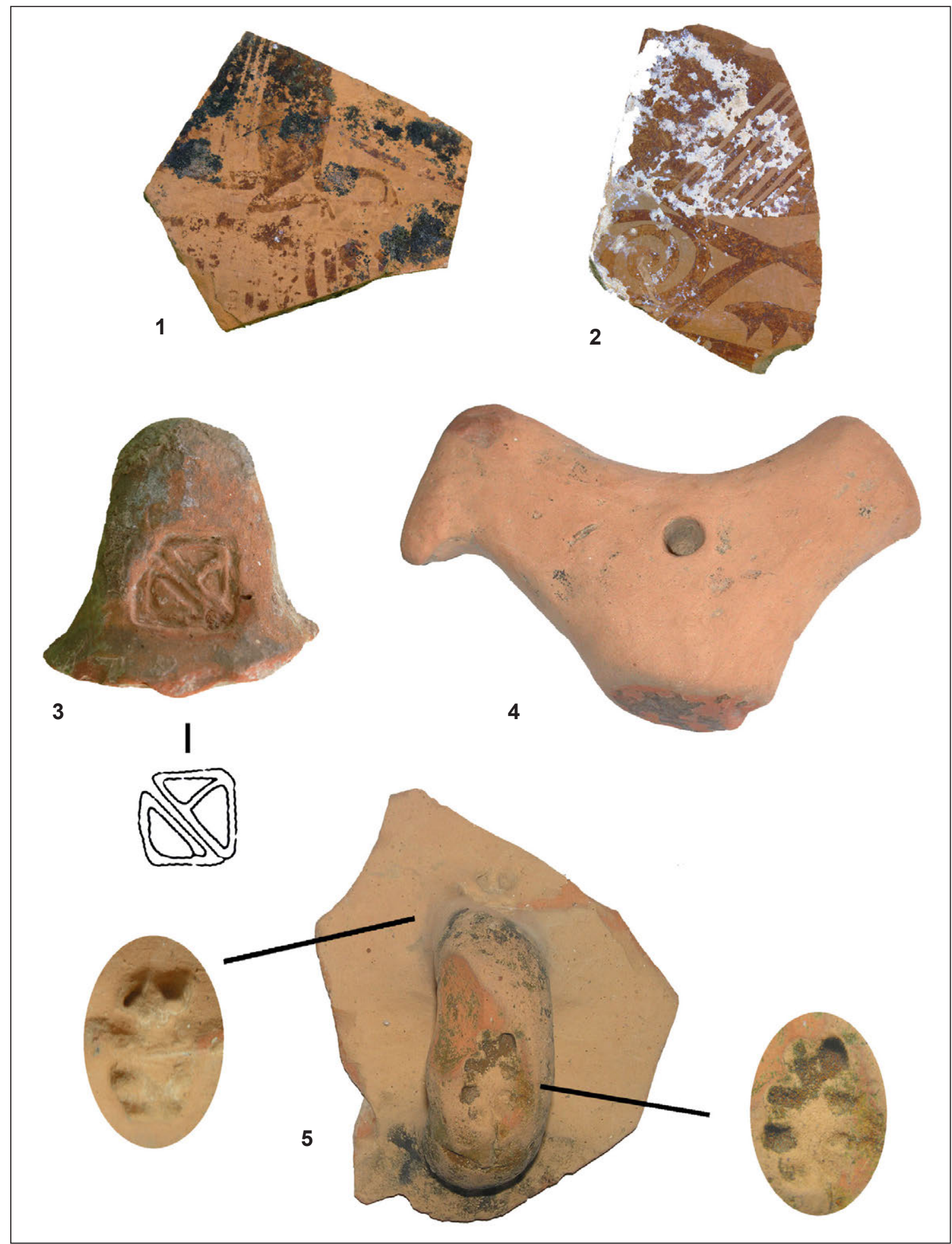

Figura 4. 1 y 2, Cerámicas con decoración compleja de Casa de la Alcantarilla (zona D); 3, Marca impresa sobre asa de ánfora ibérica de Casa de la Alcantarilla (zona C); 4, Mano de mortero de Rambla de la Alcantarilla; 5, Asa de ánfora ibérica con dos marcas impresas de Rambla de la Alcantarilla. 
propias tierras de cultivo. Su extensión, la riqueza de sus materiales y su larga diacronía apuntan a considerarlo como un pueblo, es decir, una agrupación de casas de cierta entidad, en ámbito rural, de residencia permanente (Moreno 2011: 75, tablas 9 y 10).

\section{RinCón DE HERREROS 9}

Este lagar rupestre se compone de dos piedras con sendas cubetas excavadas (figs. 5.1 y 6). Una de ellas, de forma rectangular con ángulos redondeados, fue utilizada como aljibe. Pese a ello, presenta otras características que permiten defender que se trataba de un lagar: en un extremo tiene un orificio de salida de líquido, tapado con cemento, cuyo caño por el exterior tiene dos niveles, posiblemente para colocar una cerámica o cuña de madera y facilitar la evacuación del líquido. En el borde de la balsa hay varias perforaciones en vertical que permitirían colocar una cubierta. Un poco más apartado hay un pequeño agujero de forma circular y poca profundidad, sin relación aparente con la balsa principal. A pesar de que le hemos calculado una capacidad de 2.6461 (Mata et alii 2009: Fig. 8), no hay que perder de vista que está sobredimensionada, pues la cubeta se modificó para utilizarla como aljibe.

La segunda piedra, separada de la anterior, está incompleta y presenta una cubeta circular, también de poca profundidad y con un orificio horizontal de desagüe. Posiblemente funcionaron juntas como ara de prensado, pero no se puede afirmar con seguridad. Un poco más lejos, entre la vegetación natural y el camino, se encontró otra posible estructura, muy incompleta o deteriorada.

La prospección de los alrededores proporcionó escasos fragmentos de cerámica ibérica en las viñas situadas entre el barranco y el camino paralelo a la rambla, con una dispersión estimada de $12.300 \mathrm{~m}^{2}$, pero con tres concentraciones de unos $1.500 \mathrm{~m}^{2}$. De éstas, la que proporcionó mayor cantidad de materiales era la más alejada del lagar. Todo el material cerámico pertenece a los siglos IV-III a. C. con muy pocas formas identificadas: algún asa y un plato.

${ }^{9}$ En IYAGV, de nuevo a raíz de unas prospecciones en 2010, se ha catalogado y publicado con el nombre de "Pililla del Moro Eusebio" (Martínez Valle 2014: 58).

Debemos agradecer a D. Vicente Sáez, vecino de la aldea de Los Isidros, su siempre entusiasta colaboración, al mostrarnos la localización de los lagares rupestres de Rincón de Herreros y Solana de Carbonerillas (2006), así como por facilitarnos la excavación en Rambla de la Alcantarilla, terreno por entonces de su propiedad. Su interés le ha llevado incluso a recoger algunas de las estructuras arqueológicas aquí mencionadas en sus trabajos de Historia Local (Argilés y Sáez 2008: 30-39).
Rincón de Herreros sería una estructura al aire libre que pudo tener en sus proximidades alguna casa de campo anexa a las tierras de cultivo y a las estructuras de transformación. En ella no se residiría, pero serviría de almacén de aperos y refugio para los campesinos y, posiblemente, de bodega.

\section{Solana de las Carbonerillas}

Siguiendo el camino hacia el S hay otra pila de piedra (Fig. 5.6), incompleta y desplazada de su lugar original, junto a una antigua carbonera en el cruce entre el camino principal que bordea la rambla de la Alcantarilla y otro que desciende hacia el fondo de la misma. Sólo conserva parte de una cubeta poco profunda, de tendencia rectangular, y un orificio para la salida de líquidos. La prospección de los alrededores dio resultados negativos a nivel de materiales arqueológicos.

\section{Rambla de la Alcantarilla}

Este yacimiento se visitó por primera vez en 1996 junto con Asunción y Rafael Martínez Valle, para corroborar si los bloques calcáreos tallados en forma de cubeta podían ser lagares. Dispersos a lo largo de una amplia zona hay dos lagares con seguridad (figs. 5.2 y 5.3) y un tercero que puede estar roto o inacabado (Fig. 5.4). Además, en visitas posteriores (2003 y 2005) se constató una dispersión de materiales cerámicos en unos $3.200 \mathrm{~m}^{2}$ y estructuras visibles en superficie cerca de uno de los lagares, razón por la cual se decidió hacer una campaña de excavación.

La intervención trajo a la superficie un edificio de poco más de $150 \mathrm{~m}^{2}$ construidos, de planta rectangular y varias estancias (Fig. 7.1 y 2). El grado de conservación de las estructuras y de los niveles arqueológicos era bastante deficiente, tanto por la erosión como por la vegetación. De los muros sólo se había preservado la parte inferior del zócalo de mampostería, sobre el que previsiblemente se construiría un alzado de adobes. De igual forma la documentación de los niveles arqueológicos fue complicada, ya que tanto los rellenos como los niveles de suelo estaban parcialmente alterados y conservaban poco espesor. Una vez delimitado el perímetro del edificio la excavación se centró en cada una de las estancias individualizadas. La estratigrafía y la remodelación de algunos paramentos ha permitido establecer dos fases constructivas datadas entre los siglos v y III a. C.

En el extremo $\mathrm{N}$ hay una gran estancia sin subdivisiones internas (E1), delimitada por muros de 


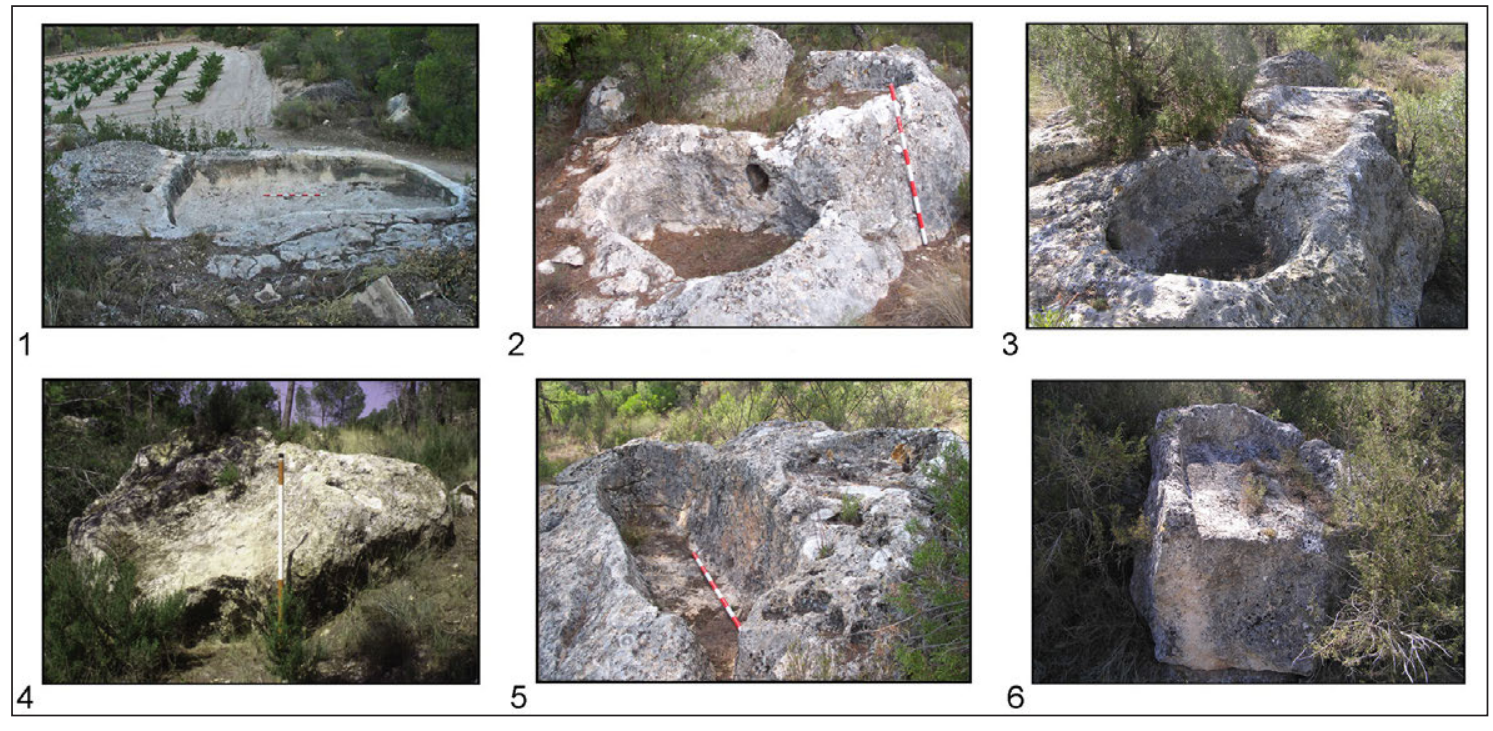

Figura 5. Lagares rupestres: 1, Rincón de Herreros o Pililla del Moro Eusebio; 2, 3 y 4 Rambla de la Alcantarilla; 6, Solana de las Carbonerillas. Almazara rupestre: 5, Solana de Cantos 2.

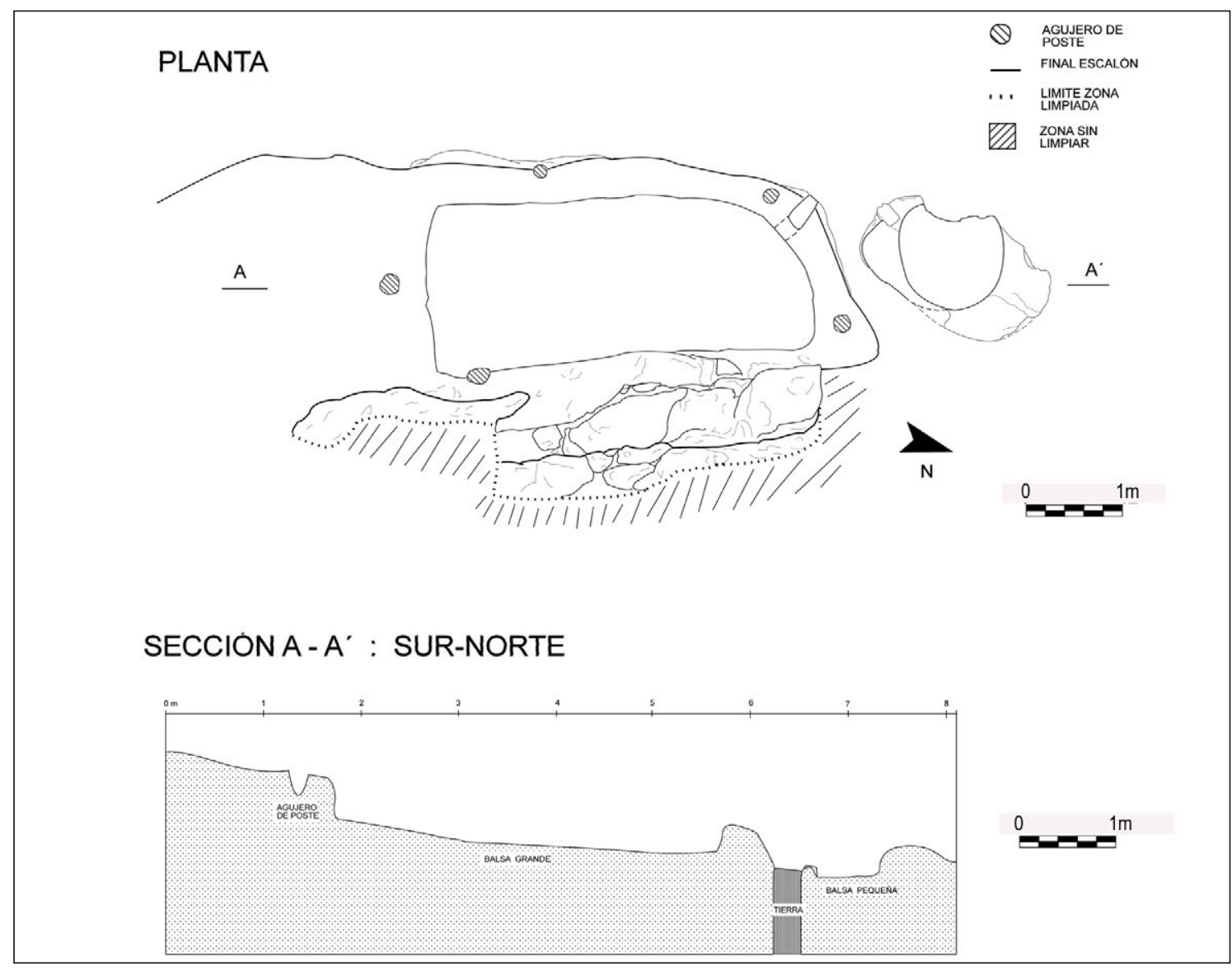

Figura 6. Planta y sección del lagar rupestre de Rincón de Herreros o Pililla del Moro Eusebio. 


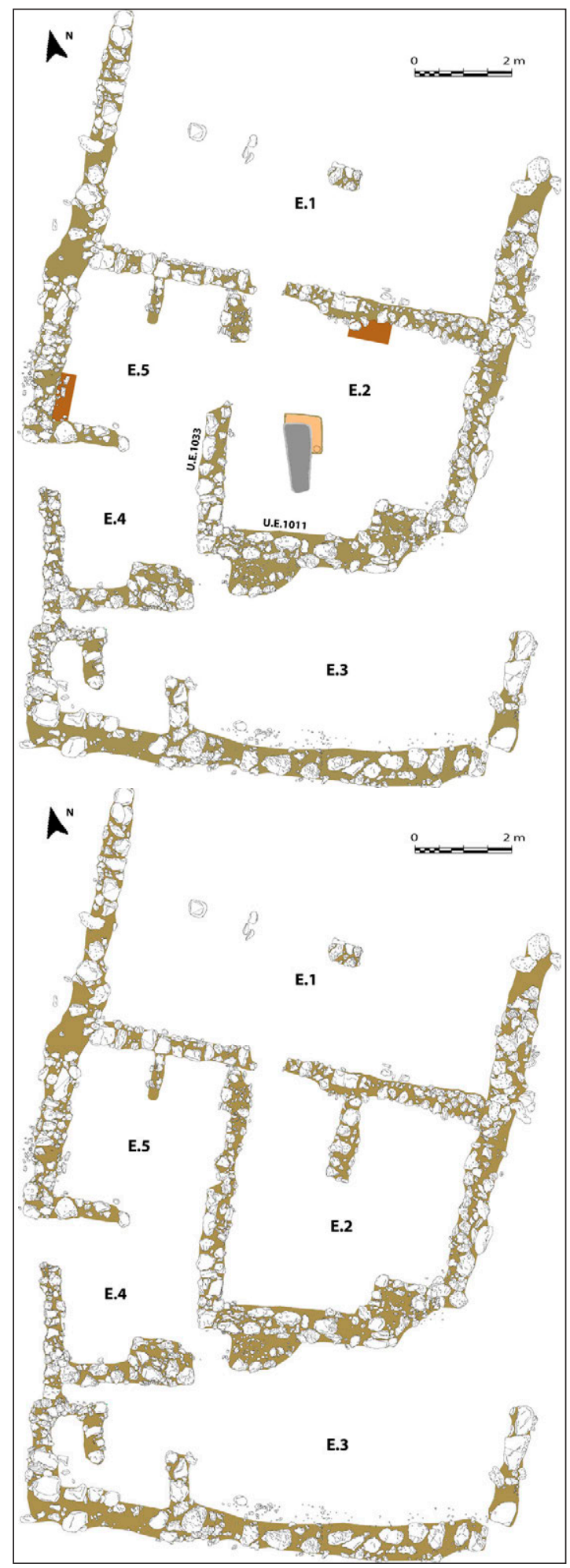

Figura 7. Planta de la bodega de Rambla de la Alcantarilla: Fase 1 (arriba), Fase 2 (abajo). mampostería por sólo tres lados (S, E y O). En la parte central hay dos estructuras de piedra de planta rectangular que debieron funcionar como bases de postes. La ubicada al O está formada por una gran piedra mientras que la del E está construida con piedras medianas y pequeñas. La ausencia del muro $\mathrm{N}$ y las dos bases de poste nos hacen suponer que esta estancia fuera, en realidad, un porche. En el muro $\mathrm{S}$ hay un vano que permite la comunicación con el cuerpo central, cubierto, del edificio. Se diferenciaron dos suelos de ocupación sucesivos. El más antiguo está construido mediante una capa de tierra roja colocada directamente sobre el sustrato original y sobre éste un relleno que funcionó como pavimento de la estancia hasta su abandono.

La parte central está formada por dos espacios que, a su vez, están compartimentados. Al E hay una gran estancia (E2) de planta rectangular, que se comunica con la E1 a través de una puerta de $1 \mathrm{~m}$ de anchura ubicada en el ángulo NO del muro medianero. Está delimitada por muros de mampostería que, en algún tramo, están construidos mediante grandes bloques o lajas de piedra caliza sin carear, dispuestos de forma vertical con un relleno de piedras y tierra.

En esta estancia también se pudieron distinguir dos niveles de uso. En el momento más antiguo es un espacio diáfano con un banco de adobes adosado al muro N. En el centro de la estancia había una almazara (Fig. 8) que conservaba una cubeta de planta rectangular excavada en el suelo con diferentes capas de enlucido de yeso. Tiene una longitud de 1,4 $\mathrm{m}$, una anchura de unos $0,3 \mathrm{~m}$ y una profundidad conservada de 0,58 m (capacidad estimada 2431 ). La base es más profunda hacia el lado $\mathrm{N}$, por donde vertería a la canal que hay construida igualmente con yeso en este lado y en la parte $\mathrm{E}$, donde acaba en un orificio circular, igualmente enlucido de yeso y con una profundidad de $0,35 \mathrm{~m}$.

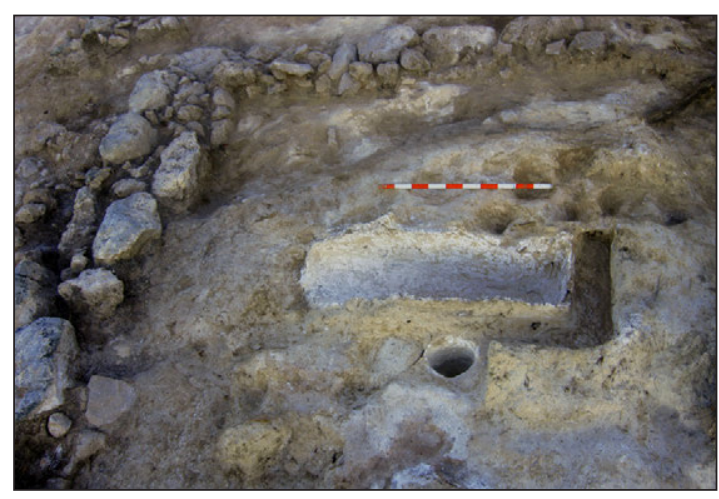

Figura 8. Almazara excavada en tierra de la fase 1 de Rambla de la Alcantarilla. 
En la fase final se anuló la almazara y se construyó un tabique que divida la estancia en dos. En la parte E había un conjunto de piedras que podrían corresponder a una base de poste. El suelo de la habitación era un simple relleno de tierra que cubría las estructuras precedentes.

Al O se encuentra la E5, también de planta rectangular. En la fase inicial estaba comunicada con la E2 a través de un vano que, posteriormente, fue sellado. Presenta un pequeño tabique en el muro $\mathrm{N}$ y un banco adosado en el ángulo SO. El suelo era una capa de yeso apisonado en cuya parte central se apreciaba una mancha circular con carbones, interpretada como los restos de un hogar. Durante el proceso de excavación no se pudo distinguir, o no se conservaba, el suelo correspondiente al momento en que se tapió la puerta de comunicación con E2.

Al S, se encuentra la E4, la más pequeña de las cinco estancias. Está separada de la E5 por un muro que deja un amplio vano de comunicación entre ambas. Es la única que presenta otra puerta de acceso hacia el $\mathrm{O}$, en dirección al lagar I, al mismo tiempo que se intuye un vano de comunicación con la E3, muy mal conservado por lo que se plantean dudas sobre su existencia real. Adosado al muro S hay un posible banco construido con mampuestos.

La E3 es otra gran estancia rectangular que delimita la construcción por el lado S. Además de la posible comunicación con la E4, presenta un amplio acceso hacia el E, posiblemente a través de una rampa. Adosado al muro $\mathrm{O}$ hay una estructura rectangular (1,9 x $1,16 \mathrm{~m})$, formada por dos muros $(0,4 \mathrm{~m}$ de ancho) de piedras medianas y pequeñas careadas por el exterior. El interior de la estructura estaba relleno de tierra y algunas piedras, de ahí que se interprete como una plataforma. Los muros que delimitan esta estancia por el S y el E están muy deteriorados e incompletos. Pese a todo, se pudo observar que para su construcción se hincaron verticalmente grandes bloques de piedra, colocando en el interior un relleno de piedras y tierra, posiblemente con la intención de construir una plataforma.

Como ya hemos apuntado, este edificio se encuentra a unos $30 \mathrm{~m}$ al E del lagar rupestre mejor conservado (Fig. 5.2). Al S de éste, bastante cerca, encontramos dos muros de 6 y 2,6 m de longitud respectivamente, por unos 0' $4 \mathrm{~m}$ de anchura en ambos casos. Sólo conservaban una hilada y no fue posible determinar si correspondían a la ocupación ibérica o a un momento posterior.

Aunque el estado de conservación de las estructuras y la escasez de sedimentación dificulta su interpretación, se puede afirmar que se trata de un edificio formado por tres estancias cubiertas situadas en el centro de la construcción (E2, E4 y E5), delimitadas por sendos espacios abiertos. La E1 con las bases de postes podría ser un área parcialmente cubierta, mientras que la E3 pudo ser un patio. Su anchura, 4 $\mathrm{m}$, es excesiva para soportar una cubierta y no se han documentado elementos sustentantes. Las remodelaciones sufridas a lo largo del tiempo no modificaron el perímetro exterior, por lo que la superficie útil apenas varió, siendo siempre de poco más de $100 \mathrm{~m}^{2}$.

En su primera fase el edificio funciona como una almazara de la que sólo se ha conservado el sistema de decantación. Es este elemento el que permite defender su uso para la obtención de aceite, ya que la decantación sólo se necesita para la separación de líquidos densos, como el aceite, del agua que contienen sus frutos. Su estructura es similar a la documentada en la vecina Solana de Cantos 2 o en las almazaras del Camp de Túria (Pérez Jordà 2000: 56-57). Es una cubeta alargada, con más profundidad que anchura, que cuenta con un sistema de decantación: un canal lateral que vierte en un orificio final. Éste es un elemento distinto a los documentados hasta el momento en la Península Ibérica, donde sólo se conocía la existencia de pequeñas depresiones construidas en el borde de las cubas; en cambio, es un sistema presente en algunas almazaras del Próximo Oriente (Callot 1984; Frankel 1999).

No se ha identificado la estructura destinada a la molturación de las aceitunas, hecho general tanto en las almazaras prerromanas de la Península Ibérica (Pérez Jordà 2000; Martínez Carmona 2014), como en todo el Mediterráneo Occidental, ya que sólo aparecen en Grecia a partir del siglo v a. C. o ya en época romana (Brun 2004: 7-10). Hay que pensar, por lo tanto, en otras formas documentadas etnológicamente, como el pisado o el chafado con morteros o rulos de piedra.

El registro tampoco aporta datos sobre la forma de prensado, aunque nos inclinamos por sugerir la existencia de una prensa de viga simple que prensaría las aceitunas sobre una plataforma o un ara de piedra que estaría ubicada junto a la balsa. El lugar más lógico sería en el ángulo formado por los muros 1033 y 1011, donde había una serie de piedras en el relleno inferior. Podemos suponer que la viga estaría incrustada en el muro 1011 y tendría una longitud máxima de unos $6 \mathrm{~m}$.

Tras la molturación, las aceitunas se introducirían en los cofines y se prensarían junto a la balsa, vertiendo el líquido al interior de la cubeta. Al mezclarlo con agua, el aceite por su densidad sube a la parte superior y va cayendo de forma progresiva en el canal construido alrededor de la cubeta, dirigiéndose a su vez hacia el orificio del lado E, de donde se extrae- 
ría para meterlo en otro recipiente y proceder a su almacenaje o decantación final.

Después de la anulación de la almazara, las actividades que se desarrollaron en su interior debieron estar relacionadas sólo con el lagar, o lagares, de las proximidades. El uso fundamental del edificio debió ser el almacenamiento de las ánforas y tinajas en las que se realizaría el proceso de fermentación del vino.

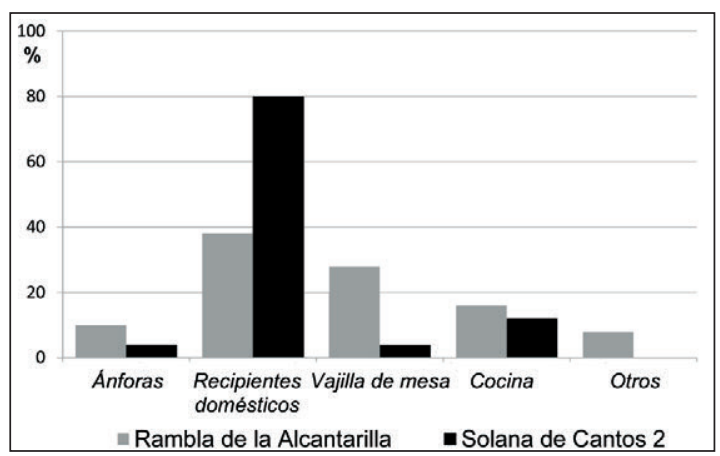

Figura 9. Porcentajes de los grupos cerámicos en Rambla de la Alcantarilla y Solana de Cantos 2.

El asentamiento presenta un corpus de materiales escaso, compuesto de un equipamiento básico. Poca variedad de formas cerámicas, la mayoría de almacén, transporte y algo de vajilla de mesa, además de abundante cerámica de cocina (figs. 9 y 10). Ánforas (figs. 10.1 a 10.4), tinajas (Fig. 10.7), lebetes y tinajillas (figs. 10.5 y 10.6) se reparten casi la mitad del total de formas cerámicas, dato acorde con las actividades llevadas a cabo en el edificio (recogida de líquido, almacenaje, fermentación, etc.). Con un conjunto tan limitado es complicado establecer fósiles directores para determinar con exactitud la cronología del lugar en cuestión, aun así hay materiales que nos remiten al siglo v a. C., como las cerámicas con decoración bicroma (Fig. 10.5), las ollas de cocina de borde reforzado con escocia (Burriel 1997: 81-83; Burriel y Mata 2013: 95, 1248-2, 1383-2 y 1209-3) (Fig. 10.10) y los bordes subtriangulares (Fig. 10.6) (Bonet y Mata 1997). Así mismo hay un plato (Fig. 10.8) de ala ancha como los ejemplares del Pla de Piquer (Alfara d'Algímia), Lloma del Manoll (Llíria), Tos Pelat (Moncada) y Solana de las Pilillas (Requena) (Aranegui y Martí 1995; Bonet y Mata 1997; Burriel y Mata 2013: 93, 1181-6; Martínez Valle 2014: Fig. 14), datados en dicho siglo V a. C. y una copa de imitación con asa horizontal, pieza también asociable con los siglos V-IV a. C. (Fig. 10.9).

La horquilla cronológica se cerraría en la segunda mitad del siglo III a. C. con piezas como un kalathos, la presencia de alguna base de pie alto o la documentación de un borde moldurado de ánfora (Fig. 10.2), tipos más frecuentes en los momentos recientes del mundo ibérico en la comarca (Quixal 2015: 54-60), y ausencia de cerámicas propias de los siglos posteriores.

Entre los materiales más destacados, sin duda debemos citar un asa de ánfora con doble marca impresa hallada en superficie (Fig. 4.5). El diseño de ambas impresiones, situadas en arranque del asa y en el centro del nervio, es muy similar a otros encontrados en Kelin y en yacimientos de su territorio, como ya se ha recogido en trabajos anteriores (Quixal et alii 2012: 65-66). Otra pieza singular es una mano de mortero con decoración zoomorfa en uno sus apéndices (Fig. 4.4), un prótomo de bovino u ovicaprino difícil de determinar al faltarle las orejas y/o cuernos, objeto con paralelos en otros yacimientos de la comarca (Mata 1991: 304 y lám. XXII; Iranzo 2004: 90, Fig. 25).

A la hora de interpretar los materiales en relación con las unidades estratigráficas en las que aparecieron, obtenemos pocos datos significativos pues el grueso de los mismos que aporta una datación apareció en niveles superficiales o de abandono. En consecuencia apenas sirven para fechar las diferentes fases de ocupación, remodelaciones y anulación de estructuras detectadas durante la excavación.

Los restos de fauna son muy escasos, apenas unos cuantos fragmentos indeterminables. En cambio, en la flotación no se recuperaron restos carpológicos, pero sí carbones en diversas muestras procedentes de los suelos de las diferentes estancias (Fig. 11). El número absoluto de fragmentos no es muy elevado (169), pero nos da una idea de los taxones vegetales leñosos que fueron explotados en el yacimiento por sus ocupantes y que, sin duda, estarían presentes en las inmediaciones del lugar.

En general, destaca la presencia de los pinos, concretamente del pino carrasco, en más de un $65 \%$ de los restos, de los que se han identificado diversos órganos vegetativos: aunque la mayor parte de los materiales corresponden a madera, se ha observado la presencia de varios fragmentos de bráctea de piña, así como algunas ramas muy jóvenes de no más de 3 ó 4 milímetros, que conservaban el diámetro completo con la corteza. En nuestra opinión, ello descarta que el material proceda de elementos constructivos a pesar de la gran abundancia de pino, una especie que se emplea frecuentemente para esta labor en los lugares de hábitat ibéricos (Grau Almero 1990; 2002; Pérez Jordà et alii 2011); además, de no existir evidencias de niveles generalizados de incendio. La presencia de ramas pequeñas que se quemarían junto a las piñas apunta a que los carbones pertenezcan a restos de combustible procedentes de fuegos no localizados, 


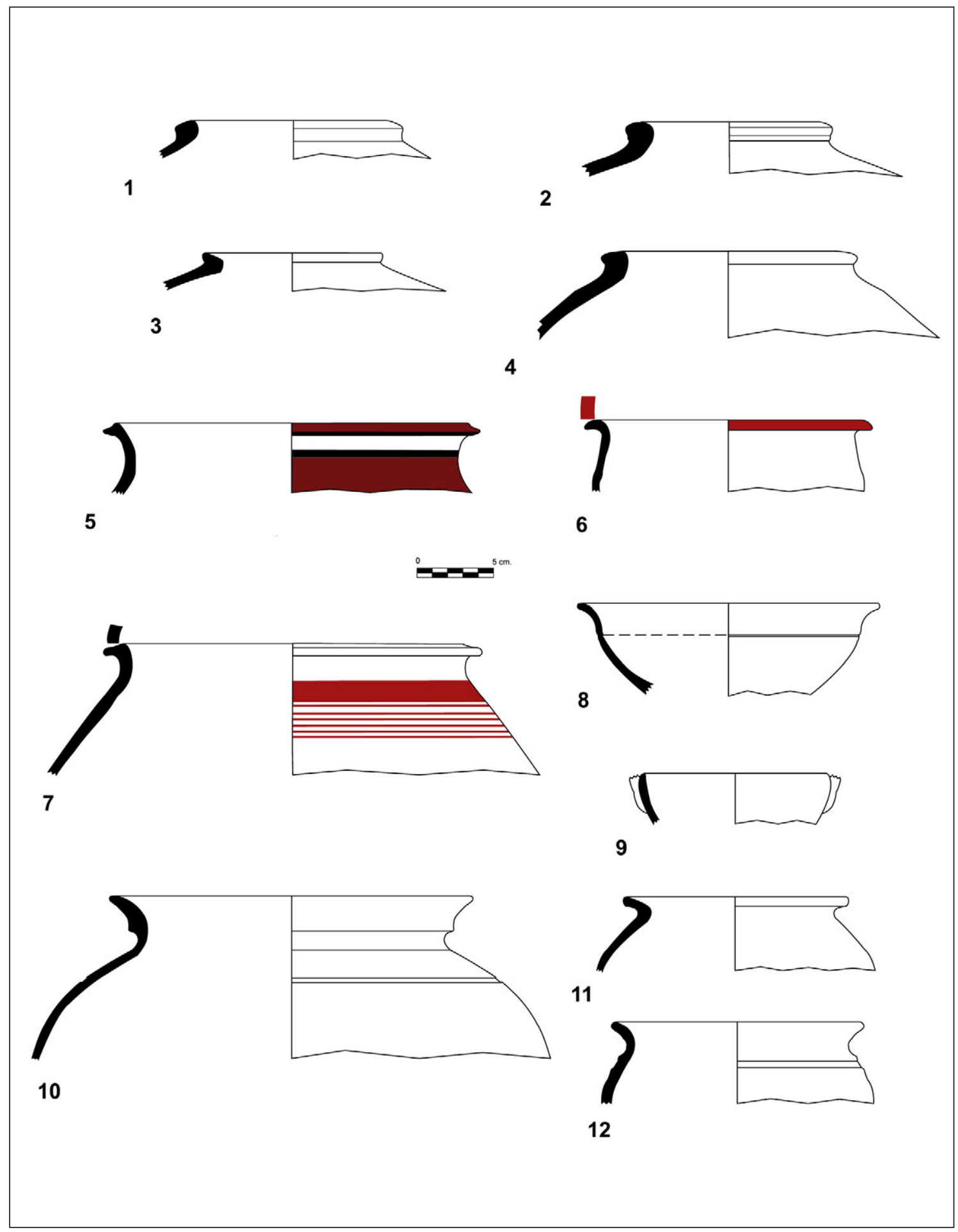

Figura 10. Cerámicas de Rambla de la Alcantarilla: 1-4, Ánforas ibéricas (UUEE 1001, 1019, 1001 y 1028); 5, Tinajilla sin hombro (UE 1016); 6, Lebes (UE 1020); 7, Tinajilla sin hombro (UE 1002); 8, Plato de ala ancha (UE 1028); 9, Copa de imitación (UE 1001); 10-12, Ollas de cocina (UUEE 1001, 1019 y 1019). 


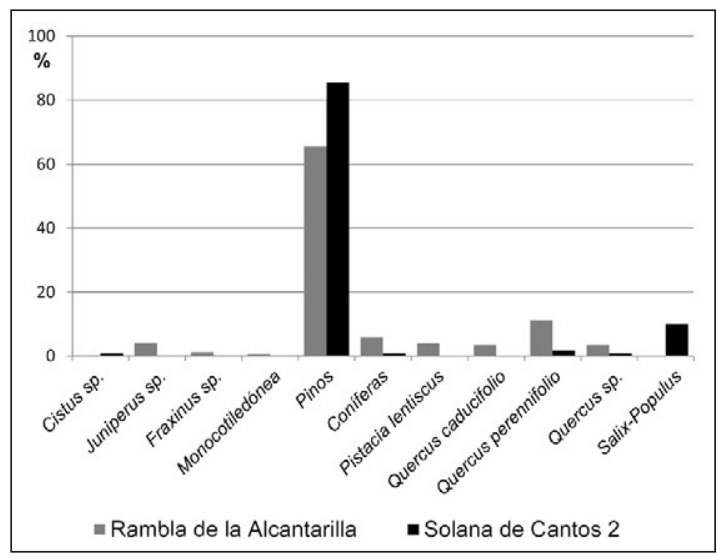

Figura 11. Porcentajes de los vegetales leñosos identificados en Rambla de la Alcantarilla y Solana de Cantos 2.

destinados a las actividades cotidianas de las personas que frecuentaron este edificio.

Además de los pinos, se utilizó en segundo lugar madera de Quercus, tanto perennifolio como caducifolio, es decir, de carrasca-coscoja y de quejigo, lo que indicaría la existencia de estas especies dentro del territorio de captación de leña. Junto a los pinos, éstos podrían dar lugar a formaciones mixtas quedando relegados los elementos caducifolios a enclaves umbrosos o a las zonas húmedas de la rambla. Otros elementos de ribera, aunque poco representados, serían los fresnos. Y, por último, los arbustos están representados por los enebros-sabinas y el lentisco.

El conjunto de taxones es perfectamente coherente con la zona en la que se encuentra el yacimiento, incluida la vegetación asociada al curso de agua, aunque éste fuera intermitente; por tanto, se demuestra que los habitantes de la Rambla de la Alcantarilla explotaron los recursos leñosos que estaban disponibles en su entorno, eso sí, parece ser que con una clara preferencia por las especies arbóreas, aunque la formación representada debió de poseer un rico sotobosque que está mal conservado en el carbón del yacimiento. Esto puede deberse a una estrategia de economizar el esfuerzo de recolección orientado a obtener especies de mayor calibre, o al uso específico del combustible, una cuestión que no podemos valorar ante la ausencia directa de las estructuras de combustión.

El edificio debió de abandonarse pacíficamente pues no hay rastro de incendio y los materiales cerámicos recuperados han sido escasos y muy fragmentados. El reducido espacio cubierto, un hogar muy precario, el dominio de recipientes cerámicos de mediano y gran tamaño, la ausencia de elementos domésticos habituales (pesas de telar, fusayolas, morteros, molinos y herramientas) así como su proximi- dad a los lagares y la presencia de una almazara no permiten pensar en un hábitat estable, siguiendo las directrices que hemos establecido en trabajos anteriores (Mata et alii 2012). Su uso sería más bien una ocupación estacional vinculada a las labores agrícolas de los campos del entorno, siendo el periodo de mayor intensidad el otoño y los inicios del invierno, coincidiendo con los procesos de la cosecha de la uva y de la aceituna y con la elaboración del vino y del aceite (Fig. 12). El lugar de hábitat permanente estaría en Casa de la Alcantarilla, el núcleo desde el que se organiza la explotación de toda esta rambla.

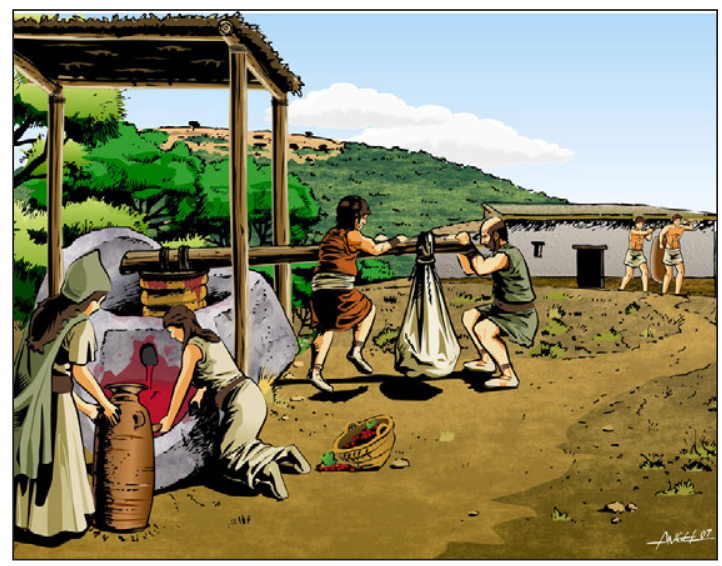

Figura 12. Reconstrucción virtual del lagar rupestre y bodega de la Rambla de la Alcantarilla (Ángel Sánchez).

\section{Solana de Cantos 2}

El lugar, en el lado opuesto de la rambla del yacimiento anterior, fue visitado por primera vez en 1996. En la ladera se localizó escaso material cerámico y una estructura excavada en un bloque calcáreo, con características que permiten clasificarla como una almazara de 4481 de capacidad (Pérez Jordà 2000: 57, Fig. 8) (Fig. 5.5). La dispersión del material alcanza unos $3.100 \mathrm{~m}^{2}$, sobre todo en la zona de piedemonte. En 2006 se hicieron cuatro sondeos en la ladera de la montaña y en la zona baja, donde se presumía que habría más probabilidades de encontrar estructuras (Fig. 13).

En la zona baja, donde se veían superficialmente algunas construcciones de piedras, se realizaron tres sondeos. Estas alineaciones apenas conservaban una hilada y cubrían un estrato de tierra margosa con algunos fragmentos de cerámica ibérica. Se puede suponer que su función era delimitar dos parcelas diferentes y acondicionar la zona para el cultivo, aunque en la actualidad no quedan restos del mismo. Faltan 


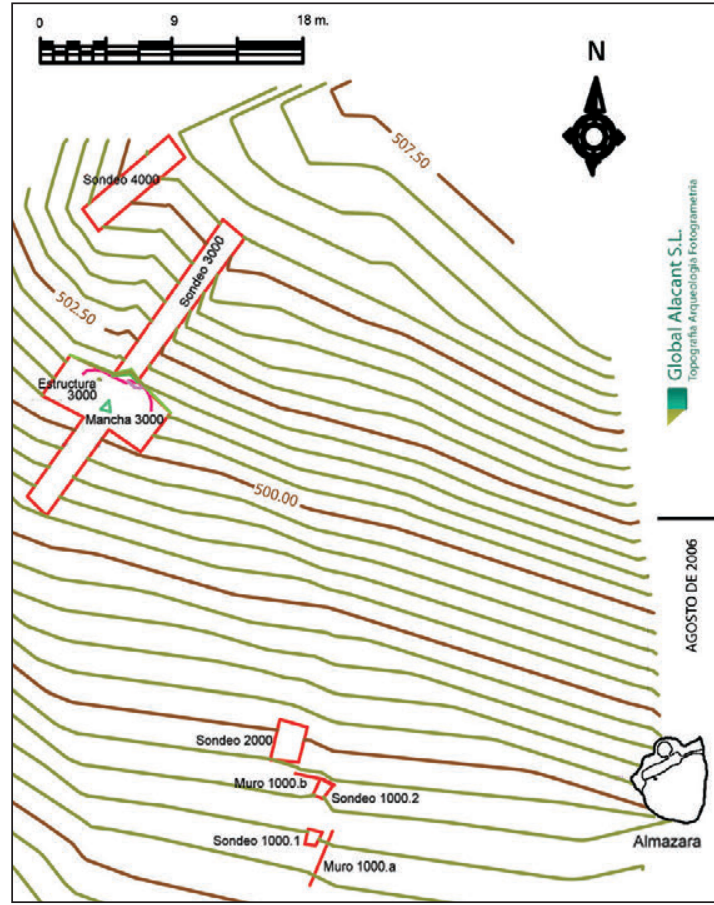

Figura 13. Planimetría general de los sondeos y estructuras de Solana de Cantos 2 .

elementos para precisar su cronología, aunque parece posterior a la ocupación ibérica de la zona y anterior al siglo xx, pues en las fotos aéreas de 1956 tampoco se aprecian restos de aterrazamientos.

En la ladera se planteó un sondeo justo en la zona en la que se observaba una mayor concentración de cerámicas. En este sentido, se abrió un área en forma de cruz con un brazo siguiendo la pendiente $(24 \mathrm{x} 2$ $\mathrm{m})$ y otro perpendicular $(8 \mathrm{x} 4 \mathrm{~m})$. La capa superficial era un estrato de tierra amarillenta de escasa potencia con muy poca materia orgánica y con algunas piedras de tamaño medio y grande. Debido a la fuerte erosión, las margas naturales emergen de forma casi inmediata excepto en la parte central donde se documentó un estrato de derrumbe de tierra margosa, con tonos marrones y anaranjados. En la base del mismo había una acumulación de piedras y entre ellas carbones aislados y una mancha formada por la combustión de unas tablas de madera (Fig. 14); éstas, sin embargo, presentaban un alto índice de fragmentación, por lo que resulta difícil aproximarse a su morfología original. Este estrato debe corresponder al derrumbe de una estructura construida que, posiblemente, sufrió un incendio.

El análisis de estos restos de madera ha dado como resultado la identificación de un alto porcentaje de madera de pino carrasco (Fig. 11), por lo que podemos

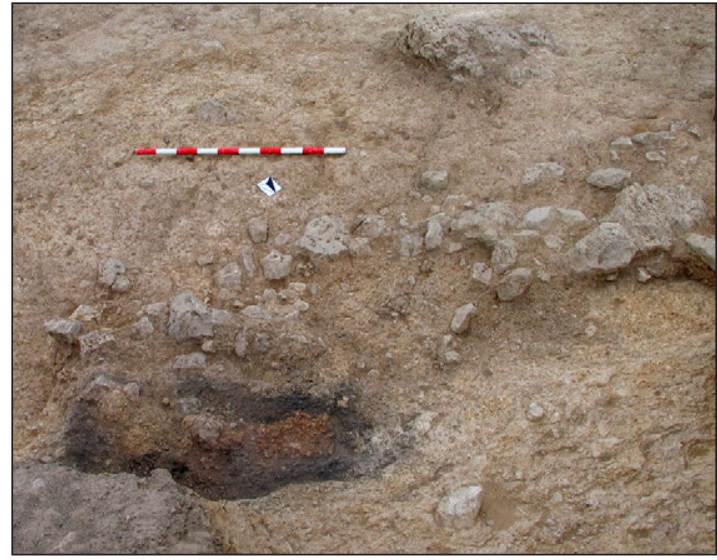

Figura 14. Estructuras localizadas en Solana de Cantos 2.

suponer que fue ésta la madera principal empleada para la elaboración de la estructura.

La presencia de otros taxones, así como de algunas ramitas de pino de pequeño calibre, nos llevan a pensar que hay otros elementos carbonizados, además de las propias tablas de madera, que podrían corresponder a restos de combustible de fuegos que se hubieran realizado durante la ocupación del lugar. Para ello, se habría de nuevo obtenido la leña de la vegetación circundante, entre la que documentamos las jaras, los Quercus y de nuevo un elemento asociado a los márgenes de la rambla, en este caso los sauces y/o chopos.

Bajo el derrumbe se definió una plataforma de poco más de $5 \mathrm{~m}$ de longitud por $2 \mathrm{~m}$ de ancho conservados, construida recortando las margas amarillentas; la altura máxima del recorte trasero es de $0,5 \mathrm{~m}$. La planta de la misma es difícil de precisar, pero en el lado $\mathrm{O}$ se puede seguir en parte, presentando un perfil irregular con los ángulos redondeados. En el centro de la estancia se conservaba una gran losa de piedra que pudo estar relacionada con el sistema de sustentación de la cubierta. Aunque se desconoce la altura real que pudo tener el recorte trasero en las margas, las viguetas del techo se apoyarían en la parte superior del mismo o bien sobre un realzado de piedras o adobe. Dicha techumbre se sustentaría en la parte frontal sobre un muro construido en el borde de la terraza, cuyos restos se encontraron, sobre la superficie de uso, en paralelo a la terraza. La fuerte erosión impidió conocer las dimensiones reales, la planta exacta y en qué lugar estaría el acceso a la construcción. Éste podría encontrarse en alguno de los laterales o bien realizarse por la parte frontal si las dimensiones de la terraza lo permitían.

Tampoco se puede descartar la posibilidad de que fuera una construcción parcialmente abierta, a modo 
de cobertizo para refugiarse durante las tareas agrícolas que se desarrollaban en las inmediaciones, ya que la almazara de piedra se encuentra a tan sólo 30 m, la bodega de Rambla de la Alcantarilla a 200 m y el caserío de Solana de Cantos 1 a tan sólo 500 m, donde habría construcciones más estables.

A pesar de la flotación del sedimento, los materiales recuperados fueron cerámicas y fragmentos óseos y carbones, sin que se aprecien grandes diferencias entre los recogidos en prospección y durante la excavación. La densidad es muy baja, así como la variedad: almacén (ánfora), despensa (lebes y tinajilla), mesa (botella) y cocina (olla y tapadera) (Fig. 9). Desde el punto de vista cronológico apenas podemos destacar que conviven bordes subtriangulares y moldurados, cerámicas de pasta gris y un borde recto de ánfora, que permiten plantear una ocupación simultánea a Rambla de la Alcantarilla, es decir, durante los siglos V-III a. C.

A pesar de la mala conservación de los restos, consideramos positiva la campaña de excavación ya que confirmó la existencia de estructuras auxiliares muy simples en el entorno de las almazaras o los campos de cultivo, que explican la localización de conjuntos limitados de materiales cerámicos o amplias dispersiones de los mismos. Como en Rincón de Herreros, podría tratarse de una casa de campo anexa a una estructura de transformación, en este caso una almazara. A diferencia de los lagares, no es necesario que haya construcciones permanentes ya que, una vez prensadas las aceitunas, el aceite no requiere un tiempo de reposo y puede trasladarse directamente al lugar de hábitat. Por su proximidad y cronología, debió formar parte del mismo complejo de transformación que la Rambla de la Alcantarilla. En la actualidad, la comunicación entre ambos puntos es compleja por la profundidad de la rambla; no obstante, dicha incisión puede ser posterior a época ibérica (Ruiz Pérez 2011).

\section{Solana de Cantos i}

Se encuentra a $500 \mathrm{~m}$ en línea recta de Solana de Cantos 2, en el mismo lado de la rambla. Se visitó en septiembre de 1996 y se trata de una dispersión de materiales de unos $7.500 \mathrm{~m}^{2}$, a lo largo de unos campos abandonados y otros plantados con vides. Tiene un registro material escaso y poco significativo, por lo que planteamos una ocupación entre los siglos V/IV- III a. C. simplemente por la ausencia de fósiles directores y su integración en la misma realidad poblacional que el resto de yacimientos de la rambla. Pese a carecer de conexión visual con los otros núcleos, planteamos que pudo ser una casería relacionada con los campos de cultivo de los alrededores y la vecina almazara.

\section{EL POBLAMIENTO Y LA PRODUCCIÓN DE VINO EN LA RAMBLA DE LA ALCANTARILLA}

Las dudas sobre la producción de vino en época ibérica en el País Valenciano se mantuvieron hasta el hallazgo a finales de los años 80 de una serie de lagares asociados a ánforas y semillas de vid en L'Alt de Benimaquia (Dénia). Este conjunto, datado a finales del siglo vir a. C., es el más antiguo de la península Ibérica a fecha de hoy (Gómez Bellard et alii 1993; Bellard y Guérin 1995).

La documentación de lagares ha ido paralela a la introducción de análisis paleobotánicos en algunas excavaciones. Éstos nos han permitido observar cómo a partir del siglo viI a. C. el cultivo de la vid y de otros frutales, como el olivo, el almendro, la higuera y el granado, se introdujo en la economía de los iberos (Pérez Jordà et alii 2000 y 2007 a). No obstante, actualmente, todavía no podemos confirmar que la extensión del viñedo vaya de la mano de una expansión de los lagares. Durante el siglo VII a. C. sólo conocemos los de L'Alt de Benimaquia, junto a una extensa circulación de ánforas de tipología fenicia (Bonet et alii 2004; Grau Mira 2007), resultado de un importante tráfico de vino que podría proceder tanto de asentamientos fenicios del Sur peninsular, como de indígenas próximos a éstos (Vera y Echevarría 2013).

Este inicio de la producción de frutales y de vino en el País Valenciano va seguido de un periodo (siglo VI a. C.) con una escasa documentación. Va a ser a partir del siglo v a. C., cuando no sólo se vuelva a constatar de forma generalizada el cultivo de frutales sino que por distintos ámbitos del área valenciana se extienden estructuras destinadas a la elaboración de vino y de aceite, tanto en los territorios de Edeta y de Kelin, como en la Illeta dels Banyets (Martínez Carmona 2014; Olcina 2005: 154-156; Pérez Jordà 2000; Pérez Jordà et alii 2013). Los lagares rupestres del territorio de Kelin debieron empezar a funcionar en este momento, a tenor de las cerámicas recuperadas en las excavaciones de las bodegas asociadas y en las prospecciones.

Así pues, la vitivinicultura inició su historia en la comarca de Requena-Utiel a partir del siglo VII a. C. cuando se documentan las primeras semillas de vitis en Kelin (Caudete de las Fuentes) (Pérez Jordà et alii 2007a: 330-331) que se completa con estructuras, de cronología posterior (siglos V-III a. C.), 
excavadas en rocas de las ramblas de la Alcantarilla y de Los Morenos.

Los primeros indicios de ocupación de la rambla en la época que nos ocupa proceden de la Casa de la Alcantarilla, que pudo fundarse en algún momento del siglo vi a. C. Este yacimiento presenta una larga diacronía, sobrepasando los límites de la propia explotación vinícola y oleícola de la rambla, ya que perdura hasta época romano imperial, mientras que los demás núcleos se abandonan entre finales del siglo III e inicios del II a. C. Por ello, y por la riqueza y diversidad de sus materiales, pensamos que sería el lugar de hábitat permanente. Ubicado en la cabecera de la rambla, tiene una visibilidad limitada por la configuración topográfica del barranco, aunque sí que tiene conexión visual directa con el lagar de Rincón de Herreros situado a poco más de $1 \mathrm{~km}$ en línea recta en el margen opuesto. Aunque la Casa de la Alcantarilla comenzara su andadura en el siglo vi a. C., la verdadera estructuración del poblamiento para la explotación de los recursos de la rambla se produciría a partir del siglo v a. C., momento del inicio de la ocupación en la mayoría de los yacimientos, independientemente de si su carácter era permanente o estacional.

En la vecina rambla de Los Morenos intuimos un modelo de poblamiento parecido. En la margen derecha se encuentra una casería o casa de labor aislada (Casa Berzosilla) y, $820 \mathrm{~m}$ aguas abajo, el asentamiento de Los Morenos, con una dispersión de materiales de casi 5 ha y muros visibles en algún punto. En este mismo entorno y a unos $100 \mathrm{~m}$ de distancia son visibles unas carriladas, en un tramo del camino que ha sido objeto de una intervención reciente (Martínez Valle 2014: 52 y Fig. 14). Los Morenos pudo ser, al igual que Casa de la Alcantarilla, el asentamiento de mayor rango donde vivirían de forma permanente varias familias, aunque en este caso con una cronología limitada a los siglos IV-III a. C. por los materiales recogidos en superficie. A unos $600 \mathrm{~m}$ hay cuatro lagares excavados en piedra a ambos lados del camino (Solana de las Pilillas) más un quinto al otro lado de la rambla. Las excavaciones iniciadas han sacado a la luz varias construcciones junto a una de ellas y, a pesar de estar mejor conservadas que las de Rambla de la Alcantarilla, tampoco se han localizado hogares ni restos bioarqueológicos. Los materiales cerámicos publicados son ánforas ibéricas, un tonel, tinajillas y platos con decoraciones propias del siglo $\mathrm{V}$ a. C., además de cuatro fragmentos de cerámica a mano tosca que son más antiguos que el conjunto anterior y proceden de diferentes unidades estratigráficas y sectores (Martínez Valle 2014: 56, Fig. 15).

Uno de los problemas que plantea el cultivo de la vid y del olivo es su escasa resistencia a las he- ladas, lo que puede causar importantes daños en las cosechas e incluso afectar a la vida de las plantas. La altitud y la orografía del altiplano de Requena-Utiel acrecientan el riesgo de heladas, por lo que parece razonable que se buscara desarrollar estos cultivos en las zonas más protegidas. La temperatura media en estas ramblas es entre $1^{\circ} \mathrm{C}$ y $2^{\circ} \mathrm{C}$ superior a la del llano y, al mismo tiempo, la intensidad y la duración del periodo de heladas es más reducida por la menor altitud y el abrigo del relieve (Ruiz Pérez 2011: 39), factores que posiblemente condicionaron la elección de esta área como un espacio centrado en estos cultivos (Pérez Jordà et alii 2013: 154), aunque no de forma exclusiva.

En este sentido, los datos antracológicos obtenidos en la Rambla de la Alcantarilla y Solana de Cantos 2 pueden estar reflejando estas condiciones más benignas. Junto a los pinos, la presencia de carrascas y quejigos, así como de fresnos, sauces y/o chopos que crecerían junto al cauce, parecen indicar la existencia de enclaves protegidos en las ramblas. Este hecho contrasta, en parte, con los datos de Kelin (Grau Almero 1991; Pérez Jordà et alii 2001), un poblado ubicado a una mayor altitud, con condiciones más frías, lo que favorece el desarrollo de los pinos de montaña.

La mayor diversidad de los taxones documentados en la Rambla de la Alcantarilla debe explicarse por cuestiones tafonómicas. En la Solana de Cantos 2 sólo se recuperó material en una estructura, mientras que en el otro caso hay diversas muestras de material disperso (Fig. 11).

Ante estos datos, resulta difícil valorar el impacto de la actividad humana sobre el medio, ya que todo apunta a que las recogidas de leña se encuentran más orientadas a taxones arbóreos o arbustivos, pudiendo ser el abanico de especies de matorral mucho más abundante de lo que reflejan las muestras. En todo caso, el desarrollo de actividades agrícolas en enclaves concretos, podría dar como resultado la expansión de los pinares alrededor de los lugares de ocupación, tal y como detectan la mayor parte de los análisis paleobotánicos para esta cronología.

Si bien es cierto que no se conocen estructuras para la elaboración de vino o de aceite en el territorio de Kelin fuera de estos (y otros) valles ${ }^{10}$, sí que hay elementos que permiten pensar en el cultivo de estos frutales en otras zonas de la meseta de Requena-Utiel. Además de la bodega documentada en la Vivienda 2 de Kelin, hay que señalar la presencia de semillas de vid en varios puntos del mismo yacimiento, así como carbones de vid y de olivo/acebuche en

${ }^{10}$ Hemos documentado nuevas estructuras junto a los ríos Cabriel y Reatillo. 
el Cerro Tocón (Requena) ${ }^{11}$, en un ambiente que no es especialmente favorable para el desarrollo de las variedades silvestres, lo que indica que su cultivo no está constreñido a la orla meridional de la comarca.

La construcción de lagares y almazaras rupestres parece responder a una explicación simplemente oportunista: la presencia de grandes bloques de piedra caliza desprendidos de las muelas de las montañas a lo largo de los siglos (Fig. 5). En ellos se han excavado algunas de las estructuras, sin que ello evite que al mismo tiempo se hayan construido otras con tierra, en el interior de los distintos edificios, como en la Rambla de la Alcantarilla (figs. 7 y 8). La ventaja de tallarlos en la roca radica en que su mantenimiento es mínimo, al ser un material mucho más resistente que las construcciones elaboradas con tierra y enlucidas en yeso, que necesitan ser mantenidas continuamente. Al mismo tiempo no ocupan espacio en el interior de una vivienda y únicamente se limpiarían cuando fueran a utilizarse.

La construcción o la excavación de lagares y almazaras fuera de las zonas de hábitat, supuestamente junto a los campos de vides u olivos, es una práctica documentada en el Mediterráneo Oriental al menos desde el III milenio a. C. (Callot 1984; Frankel 1999). En la península Ibérica, estas estructuras rupestres son hasta el momento las más antiguas, pero será una práctica que se mantendrá hasta, al menos, el siglo XIX d. C. ${ }^{12}$. El motivo que, en algunos casos, explica su construcción es la puesta en cultivo de campos en zonas alejadas de los lugares de hábitat. De esta forma se evita el traslado de los frutos durante el periodo de la recolección y se puede transportar el producto ya elaborado de forma más cómoda.

Ejemplos similares se pueden encontrar en la Cataluña interior durante los siglos XVIII-XIX d. C. con lagares que están en el interior de espacios cubiertos (Ferrer i Alós 2003) y durante los siglos X-XIII d. C. en La Rioja, con simples estructuras aisladas aparentemente sin espacios construidos junto a las mismas (Palacios y Rodríguez 2009).

El mosto, antes de fermentar o al finalizar la parte tumultuosa, debería ser trasladado a las tinajas o ánforas que quedarían almacenadas ya en el interior de las viviendas anejas, que funcionarían en realidad como auténticas bodegas. En el caso de las almazaras cabe la posibilidad de que el proceso fuera similar o que

\footnotetext{
${ }^{11}$ Informe inédito de M. Ntinou sobre los carbones de la excavación de Cerro Tocón con motivo del trazado del AVE, dirigida por M. A. Valero Tévar en 2006.

${ }^{12}$ En Junio de 2010 se celebró el congreso "Lagares, pilas y lagaretas. Paisaje y producción" en Labastida y San Vicente de la Sonsierra, cuyas actas han sido recientemente publicadas (Contreras y Elias, 2015).
}

por el contrario se produjera un traslado inmediato del aceite a los poblados, puesto que tras el prensado es un producto ya elaborado. Pero efectuar un traslado del mosto o del vino tras la primera fermentación, como se sugiere en las estructuras de La Rioja, resulta problemático, ya que el vino está aún en proceso de elaboración y aumentan las posibilidades de estropear el producto.

Siguiendo el sistema de organización que hemos propuesto en anteriores trabajos (Pérez Jordà et alii 2013), los habitantes de la Casa de la Alcantarilla serían los que cultivarían los campos de vides y olivos que plantaron en esta rambla, mientras que asegurarían su sustento a partir de los cultivos anuales (cereales y leguminosas) que desarrollarían en las tierras inmediatas al asentamiento, más ricas que las dedicadas al cultivo de los frutales. Posiblemente las parcelas se estructurarían en torno al cauce de agua que discurriría por la parte central del valle, con algún sistema que asegurara la evacuación de las aguas hacia este arroyo y dejando al menos un camino de circulación en la base de la ladera, de una forma similar a la documentada en Saint-Jean-du-Désert, en el entorno de Marsella (siglos IV-II a. C.) (Boissinot 2001). No es posible determinar si la totalidad de la superficie potencialmente explotable fue puesta en cultivo o si los campos sólo estaban junto a los distintos lagares y almazaras (Pérez Jordà et alii 2013: 153-154, Fig. 5). La estimación realizada de suelos potencialmente cultivables es de unas 43 ha en el entorno del Rincón de Herreros y de 28 ha en la Rambla de la Alcantarilla. Superficie que en el caso de estar totalmente dedicada al cultivo de estos dos frutales exigiría el trabajo de una cantidad importante de mano de obra. Siguiendo la valoración de 147 jornadas por hectárea y año para el cuidado de un viñedo (Gallant 1991: 75-76), el mantenimiento de toda esta superficie podría necesitar del concurso anual de unas 34 personas. Esfuerzo que en los primeros años sería mucho mayor por la necesidad de acondicionar los campos, excavar las zanjas o cubetas para plantar las viñas y cuidarlas durante varios años hasta que se iniciara la producción. En este caso no se trataría, por tanto, de pequeñas explotaciones familiares que dedican una parte de sus parcelas a un cultivo complementario que pueda tener algún valor especulativo o comercial, sino que se realiza una inversión destacada en el cultivo de dos frutales. Ello exigiría necesariamente un cierto grado de organización, algo habitualmente asociado a la acción de grandes terratenientes o a sociedades con formas estatales (Zamora 2000: 144).

No es tarea fácil estimar la población de los diferentes lugares de hábitat y más aún si no se cuenta con excavaciones en extensión. Sin embargo, la cifra 
propuesta de 34 personas útiles para el trabajo en el campo no es inalcanzable teniendo en cuenta la existencia de un asentamiento como la Casa de la Alcantarilla.

Además de la aproximación a la superficie cultivada, también es interesante realizar un cálculo sobre la cantidad de vino que se podría producir (Mata et alii 2009: 138, Fig. 8; Pérez Jordà et alii 2013: 156). En el caso de Rambla de la Alcantarilla sería de algo más de 30001 , teniendo en cuenta los dos lagares incompletos (Solana de las Carbonerillas y lagar II de Rambla de la Alcantarilla). Este cálculo no se puede realizar para el aceite ya que este producto no necesita un periodo mínimo de reposo, aunque una almazara como la de la Rambla de la Alcantarilla tiene una capacidad muy pequeña; mientras que otras, como la de Solana de Cantos 2, con un ara de prensado y una cuba de mayores dimensiones, tendría una producción más destacada.

Las cifras obtenidas para todos los lagares conocidos son superiores a las del territorio edetano y cercanas a las proporcionadas por la Illeta dels Banyets (Mata et alii 2009: Fig. 8). En consecuencia, una parte de la producción se dedicaría al autoconsumo, pero otra necesariamente podría dirigirse al mercado comarcal o regional. De este modo los productores de vino y aceite conseguirían aquellos bienes que no producen y de los que son deficitarios, como recipientes cerámicos, útiles metálicos y objetos de prestigio, entre otras cosas.

Los beneficiarios de esta producción serían los habitantes de los poblados fortificados (Muela de Arriba, Cerro de la Cabeza, Requena, etc.) y de la ciudad, Kelin, ya que en esos lugares es donde se concentran los bienes de prestigio, tanto cerámicos como metálicos o de otra índole, distanciándose considerablemente de los restos que se han documentado en la propia Casa de la Alcantarilla. Otro de los aspectos que permite ilustrar mejor esta idea es la presencia de marcas precocción sobre ánfora en la comarca, algunas de ellas idénticas (figs. 4.3 y 4.5 ) $^{13}$, que permiten plantear redes de distribución del vino y el aceite desde los lugares de producción (Casa y Rambla de la Alcantarilla; Los Morenos y Solana de las Pilillas) hacia el lugar central (Kelin), donde se ha documentado una importante bodega en una de las

\footnotetext{
${ }^{13}$ Tras Cataluña, la comarca de Requena-Utiel es la zona donde se documenta una mayor concentración de marcas precocción, fenómeno que ya se podía apreciar desde finales de siglo pasado y que no ha hecho más que corroborarse desde entonces (Soria y Mata 2015). Las marcas se han encontrado entre otros lugares en Kelin, Casillas del Cura, Casa y Rambla de la Alcantarilla (Mata y Soria 1997: Fig. 1; Soria y Mata 2015); Martínez Valle 2014: 63, Fig. 19).
}

viviendas y el mayor número de marcas sobre ánfora de toda la comarca (Mata et alii 1997; Mata y Soria 1997; Soria y Mata 2015).

En definitiva, este sistema de poblamiento rural, de explotación de la tierra y de producción lleva implícita una organización socio-política compleja, que genera y sustenta redes a escala local y regional, dejando entrever una clara estratificación social, donde los campesinos se dedican a la producción, pero las redes de distribución y comercialización quedan en manos de las elites, que serían las beneficiarias últimas de todo el proceso.

\section{BIBLIOGRAFÍA}

Aranegui, C. y Martí, M. A. 1995: "Cerámicas procedentes de un alfar ibérico localizado en el Pla de Piquer (Alfara d'Algímia) cerca de Sagunt (València)", Saguntum 28, 131-149.

Argilés, V. y Sáez, V. 2008: De vuelta por el Municipio de Requena. La Albosa requenense, Requena.

Boissinot, P. 2001: «Archéologie des vignobles antiques du sud de la Gaule», Gallia 58, 45-68. http://dx.doi.org/10.3406/galia.2001.3173

Bonet, H., Garibo, J., Guérin, P., Mata, C., Valor, J., y Vives-Ferrándiz, J. 2004: "Las ánforas importadas de las comarcas centrales del País Valenciano", Arqueo Mediterránia, 8, 203-227.

Bonet, H. y Mata, C. 1997: "La cerámica ibérica del siglo V a. C. en la Edetania", Recerques del Museu d'Alcoi 6, 31-48.

Brun, J. P. 2004: Archéologie du vin et de l'huile. De la préhistoire à l'époque hellénistique, Paris.

Burriel, J. 1997: «La cerámica tosca del Tos Pelat (Montcada, Valencia)», Intervenció $i$ Patrimoni 1, 163-174.

Burriel, J. y Mata, C. 2013: “L'oppidum ibèric d'El Tos Pleat de Moncada) (L'Horta Nrd, València)", Monte Catano 14, 75-97.

Callot, O. 1984: Les huileries antiques de Syrie du Nord, Paris.

Contreras, M. y Elias, L. V. (eds.) 2015: Lagares rupestres. Aportaciones para su investigación, Vitoria.

Ferrer i Alós, L. 2003: "Tines a casa, tines al mas, tines enmig de les vinyes a la Catalunya central", Els paisatges de la vinya, 147-156.

Frankel, R. 1999: Wine and oil production in Antiquity in Israel and other Mediterranean countries, Sheffield.

Gallant, T. W. 1991: Risk and survival in ancient Greece. Reconstructing the rural domestic economy, Cambridge. 
Gómez Bellard, C. y Guérin, P. 1995: “Los lagares del Alt de Benimaquia (Denia): en los inicios del vino Ibérico", S. Celestino Pérez (ed.), Arqueología del vino. Los orígenes del vino en Occidente, Jerez de la Frontera, 241-270.

Gómez Bellard, C., Guérin, P. y Pérez Jordà, G. 1993: «Témoignage d'une production de vin dans l'Espagne préromaine», Bulletin de Correspondance Hellénique, suppl. XXVI, 379-395.

Grau Almero, E. 1990: El uso de la madera en yacimientos valencianos de la Edad del Bronce a época visigoda. Datos etnobotánicos y reconstrucción ecológica según la antracología, Tesis Doctoral. Universitat de València.

Grau Almero, E. 1991: "Apéndice IV. Análisis antracológico", C. Mata, Los Villares (Caudete de las Fuentes): origen y evolución de la cultura ibérica, Trabajos Varios del SIP 88, Valencia, 261-264.

Grau Almero, E. 2002: "Paleoambiente y gestión del bosque", H. Bonet Rosado y C. Mata Parreño, El Puntal dels Llops. Un fortín edetano, Trabajos Varios del SIP 99, Valencia, 169-171.

Grau Almero, E., Pérez Jordà, G., Iborra, P. y de Haro, S. 2001: "Medio ambiente, agricultura y ganadería en el territorio de Kelin en época ibérica", A. Lorrio (coord.), Los Íberos en la comarca de Requena- Utiel (Valencia), Anejo de la revista Lucentum 4, Alicante, 89-103.

Grau Mira, I. 2007: "Dinámica social, paisaje y teoría de la práctica. Propuestas sobre la evolución de la sociedad ibérica en el área central del Oriente peninsular", Trabajos de Prehistoria 64, 2, 119 142. http://dx.doi.org/10.3989/tp.2007.v64.i2.112

Iranzo, P. 2004: Arqueología e Historia de Sinarcas, Utiel.

Martínez Carmona, A. 2014: Una almazara ibérica en el yacimiento de la Illeta dels Banyets (El Campello, Alicante), M. H. Olcina y J. Soler (eds.) Arqueología en Alicante en la primera década del siglo XXI. II Jornadas de Arqueología y Patrimonio Alicantino, MARQ, Alacant, 247-253.

Martínez Valle, A. 2014: "La Solana de las Pilillas y otros testimonios de producción y consumo de vino en la Meseta de Requena-Utiel", Lucentum XXXIII, 51-72. http://dx.doi.org/10.14198/lvcentvm2014.33.04

Martínez Valle, A. y Hortelano, L. 2011: “Ánforas vinarias de Casillas del Cura (Venta del Moro) y Solana de las Pilillas (Requena). Caracterización, similitudes y diferencias”, Oleana 26, 71-88.

Martínez Valle, A. y Maronda, M. ${ }^{a}$ J. 2013: "Testimonios de viticultura durante la Antigüedad en la comarca de Requena-Utiel (Valencia)", Patrimonio cultural de la vid y el vino, 177-187.
Martínez Valle, A., Martínez Valle, R. y Maronda, M J. 2011: "La Solana de las Pilillas: génesis de la viticultura en la comarca de Requena-Utiel", Oleana 26, 13-29.

Mata, C. 1991: Los Villares (Caudete de las Fuentes): origen y evolución de la cultura ibérica, Trabajos Varios del SIP 88, Valencia.

Mata, C. 2006: "El ibérico antiguo de Kelin/Los Villares (Caudete de las Fuentes, València) y el inicio de su organización territorial", M. C. Belarte Franco y J. Sanmartí Grego (eds.) De les comunitats locals als estats arcaics: la formació de les societats complexes a la costa del Mediterrani occidental, Arqueo Mediterrània, 9, Barcelona, 123-134.

Mata, C. y Bonet, H. 1992: "La cerámica ibérica: ensayo de tipología”, Trabajos Varios del SIP 89, 117-173.

Mata, C., Duarte, F. X., Ferrer, M. A., Garibo, J. y Valor, J. 2001: "Kelin (Caudete de las Fuentes, València) y su territorio", A. Lorrio (coord.) Los Íberos en la comarca de Requena-Utiel, Anejo de la revista Lucentum 4, Alicante, 75-87.

Mata, C., Moreno, A., Pérez Jordà, G., Quixal, D. y Vives-Ferrándiz, J. 2009: "Casas y cosas del campo: hábitat agrícola y estructura social en los territorios de Edeta y Kelin (siglos V-III a.n.E)", Arqueo Mediterrània 11, Barcelona, 143-152

Mata, C., Moreno, A. y Quixal, D. 2010: "Hábitat rural y paisaje agrario durante la segunda Edad del Hierro en el este de la Península Ibérica", International Congress of Classical Archaeology. Meetings between cultures in the ancient Mediterranean (Roma 2008). Bolletino di Archeologia on line, volume speciale, 32-46. http://151.12.58.75/ archeologia/index.php?option=com_content \&vie $\mathrm{w}=$ article $\& \mathrm{id}=11 \&$ Itemid $=11$.

Mata, C., Moreno, A. y Quixal, D. 2012: "Estrategias de ocupación y explotación del entorno periurbano de Kelin", El paisatge periurbà a la Mediterrània occidentaldurant la protohistòria i l'antiguitat. Actes del Col-loqui internacional, Institut Català d'Arqueologia Clàssica, Tarragona, 183-198.

Mata, C., Pérez Jordà, G. e Iborra, Mª P. 2005: "Les activitats econòmiques dels pobles ibers al País Valencià", XIII Col-loqui Internacional de Puigcerdà Puigcerdà, 2, 737-767.

Mata, C., Pérez Jordà, G., Iborra, M ${ }^{\mathrm{a}}$ P. y Grau A1mero, E. 1997: El vino de Kelin, Utiel.

Mata, C. y Quixal, D. (2014): "El territorio de Kelin: un espacio secundario de producción y circulación de imitaciones en el interior valenciano (ss. VII a. C. - I d. C.)", R. Morais, A. Fernández y M. J. Sousa (eds.), As produções cerâmicas de imitação na Hispania, Monografias Ex Officina Hispana II, Braga, 2, 51-59. 
Mata, C. y Soria, L. 1997: "Marcas y epígrafes sobre contenedores de época ibérica", Archivo de Prehistoria Levantina XXII, 297-374.

Moreno, A. 2011: Cuando el paisaje se convierte en territorio: Aproximación al proceso de territorización íbero en la Plana d'Utiel, València (ss. VI-II ane), BAR Int. Series 2298, Oxford.

Olcina, M. H. 2005: "La Illeta dels Banyets, El Tossal de Manises y La Serreta", L. Abad, F. Sala e I. Grau (eds.), La Contestania ibérica, 30 años después, Alicante, 147-177.

Palacios, V. y Rodríguez Fernández, J. 2009: “Un ejemplo de explotación agraria en la temprana Edad Media. La viticultura en la Sonsierra alavesa (siglos IX a XIII)", J. A. Quirós Castillo (ed.), The Archaeology of early medieval villages in Europe, Vitoria, 447-452.

Pérez Jordà, G. 2000: "La conservación y la transformación de los productos agrícolas en el Mundo Ibérico", Saguntum Extra 3, Valencia, 47-68.

Pérez Jordà, G., Alonso, N. e Iborra, Mª P. 2007 “Agricultura y ganadería protohistóricas en la península Ibérica: modelos de gestión", A. Rodríguez e I. Pavón (eds.), Arqueología de la la tierra. Paisajes rurales de la protohistoria peninsular, Cáceres, 327-373.

Pérez Jordà, G., de Haro, S., Iborra, M ${ }^{\mathrm{a}}$ P. y Grau Almero, E. 2001: "Medio ambiente, agricultura y ganadería en el territorio de Kelin en época ibérica", A. Lorrio (coord.), Los íberos en la comarca de Requena-Utiel (Valencia), Anejo de la revista Lucentum 4, Alicante, 89-104.

Pérez Jordà, G., Ferrer, C., Iborra, Mª P., Ferrer, M. A., Carrión, Y., Tortajada, G. y Soria, L. 2011: “El trabajo cotidiano. Los recursos agrarios, la metalurgia, el uso de la madera y las fibras vegetales", H. Bonet y J. Vives-Ferrándiz (eds.), La Bastida de les Alcusses. 1928-2010, Valencia, 94-137.

Pérez Jordà, G., Iborra, Mª P., Grau Almero, E., Bonet, H. y Mata, C. 2000: "La explotación agraria del territorio en época ibérica: los casos de Edeta y Kelin", XXII Col-loqui Internacional per l'Estudi de l'Edat del Ferro, Sèrie Monogràfica 18, Girona, [1999], 151-167.

Pérez Jordà, G., Mata, C., Moreno, A. y Quixal, D. 2007b: "L'assentament ibèric del Zoquete (Requena, València): resultats preliminars de la $1^{\text {a }}$ campanya d'excavació", Saguntum 39, 185-187.

Pérez Jordà, G., Mata, C., Moreno, A. y Quixal, D. 2013: "Stone winepress and cellars in the Iberian territory of Kelin (Utiel-Requena) (6th-2nd centuries BC)", Paisajes y patrimonio cultural del vino y de otras bebidas psicotrópicas, Requena, 149-158.

Pérez Jordà, G., Mata, C., Moreno, A. y Quixal, D. 2015: "Lagares de piedra y bodegas en el territo- rio ibérico de Kelin (Comarca de Utiel-Requena, València)", M. Contreras y L. V. Elias (coords.), Lagares rupestres. Aportaciones para su investigación, Adra, La Rioja, 61-70.

Quixal, D. 2015: La Meseta de Requena-Utiel entre los siglos II a. C. y II d.C.: la Romanización del territorio ibérico de Kelin, Trabajos Varios del SIP 118, Valencia.

Quixal, D., Mata, C., Albelda, V. y Pérez Reyes, A. 2010: "Primera campaña de excavación en el asentamiento ibérico final de la Casa de la Cabeza (Requena, València)", Saguntum, 42, 115-117.

Quixal, D., Mata, C., Albelda, V. y Pérez Reyes, A. 2011: "Segunda campaña de excavación en el asentamiento ibérico final de la Casa de la Cabeza (Requena, València)", Saguntum 43, 205-208.

Quixal, D., Mata, C., Albelda, V., Pérez Reyes, A. y Sancho, L. 2012a: "Tercera campaña de excavación en el asentamiento ibérico final de la Casa de la Cabeza (Requena, València)", Saguntum 44, 185-188.

Quixal, D., Moreno, A., Mata, C. y Pérez Jordà, G. 2008: "L'assentament ibèric del Zoquete (Requena, València)", Saguntum 40, 233-236.

Quixal, D., Pérez Jordà, G., Moreno, A. y Mata, C. 2012b: "Origen y evolución de la vitivinicultura en la Meseta de Requena-Utiel entre los siglos VII a. C. y II d. C.", Oleana 26, 57-69.

Ruiz Pérez, J. M. 2011: "Geomorfología y paisaje del entorno de la Solana de las Pilillas y ramblas de Los Morenos y Alcantarilla (Requena, Valencia)", Oleana 26, 31-56.

Sánchez Priego, J. A., Molina, Ll., Carrión, Y., Ruiz Pérez, J. M. y Morales, J. V. 2010: “Avenida de la Fuente (Siete Aguas, Valencia): un nuevo asentamiento calcolítico en el interior valenciano", Archivo de Prehistoria Levantina XVIII, 207-239.

Soria, L. y Mata, C. 2015: "Marcas y epígrafes sobre ánforas de época ibérica. II", Lucentum XXXIV, 145-171. http://dx.doi.org/10.14198/ lvcentvm2015.34.05

Vera, J. C. y Echevarría, A. (2013): "Sistemas agrícolas del I milenio a. C. en el yacimiento de la Orden-Seminario de Huelva. Viticultura protohistórica a partir del análisis arqueológico de las huellas de cultivo", S. Celestino y J. Blánquez (eds.), Patrimonio Cultural de la vid y del vino, Jérez de la Frontera, 95-106.

Zamora, J. A. 2000: La vid y el vino en Ugarit, Banco de datos filológicos semíticos noroccidentales, Monografías 6, CSIC, Madrid.

Recibido: 19-01-2015

Aceptado: 22-04-2015 